\title{
Ocorrência de horizonte cromífero no Complexo Trincheira, município de Corumbiara, sudeste de Rondônia
}

\author{
Guilherme F. da Silva (guilherme.ferreira@cprm.gov.br) \\ Thyago de J. Ribeiro (thyago.ribeiro@cprm.gov.br) \\ Lívio W. C. Corrêa (livio.correa@cprm.gov.br) \\ Dalton R. V. da Silva (dalton.rosemberg@cprm.gov.br) \\ Carlos E. S. de Oliveira (carlos.oliveira@cprm.gov.br)
}

CPRM - Serviço Geológico do Brasil, REPO - Residência de Porto Velho

\begin{abstract}
The Trincheira Mafic-ultramafic Complex comprises a Mesoproterozoic layered intrusion hosted in metasedimentary rocks of the southwestern portion of the Amazonian Craton. This intrusion has an outcropping area of approximately $35 \mathrm{~km}^{2}$, however, it has been associated to a larger ellipsoidal magnetic anomaly with N-S elongated shape. The Trincheira Complex is composed of partially metamorphosed pyroxenites, websterites, gabbros and anorthosites. The complex hosts $\mathrm{Cr}$-rich layers associated to relevant concentrations of $\mathrm{Ni}$. High concentrations of $\mathrm{Cu}, \mathrm{Co}$ and $\mathrm{V}$ have also been detected. Preliminary analysis performed with portable X-ray diffraction indicates up to $13 \% \mathrm{Cr}$ and occurrence of cochromite, a special variety of chromite enriched in cobalt, nickel and iron, whereas ICP-MS analyses returned concentrations of up to $\sim 3600 \mathrm{ppm} \mathrm{Cr}$.
\end{abstract}

Keywords: Mafic-ultramafic intrusions. Cumulatic rocks. Amazonian Craton.

Palavras-chave: Intrusões máfico-ultramáficas. Rochas cumuláticas. Cráton Amazônico.

\section{INTRODUÇÃO}

Novas ocorrências minerais foram identificadas em rochas ultramáficas do Complexo Trincheira, sudeste do Estado de Rondônia, localizadas na Fazenda Patuá (ou Andreazza), situada às margens da rodovia estadual RO-370, "Estrada do Boi", município de Corumbiara, próximo à divisa entre o estado de Mato Grosso e fronteira com Bolívia (Figura 1).

Neste informe são apresentados dados petrográficos, analíticos de difração e fluorescência de raios-X, litogeoquímicos e geofísicos-magnetométricos.

As análises das rochas máfico-ultramáficas indicam uma amostra com teores relevantes de cromo (3624 ppm), níquel (1829 ppm) e cobalto (651 ppm), acompanhados de teores menores de cobre (470 ppm) e vanádio (318 ppm).

Tendo em vista que estas ocorrências se encontram hospedadas no Complexo Trincheira, o qual apresenta semelhanças com os corpos ultramáficos descritos no Morro Sem Boné e Morro do Leme, mineralizados em Ni, espera-se que os dados apresentados chamem atenção para novas áreas de pesquisas voltadas para investigação da potencialidade de depósitos minerais relacionados a corpos máfico-ultramáficos.

\section{CONTEXTO GEOLÓGICO}

O Complexo Trincheira foi definido por Romanini (2001) como uma associação de "rochas máfico-ultramáficas intrusivas na Sequência Metavulcanossedimentar Nova Brasilândia, constituindo-se de gabros, gabro-noritos, tremolititos, websteritos e bronzititos, parcialmente metamorfisados em fácies xisto verde alto, tendo superfície aflorante de apro-ximadamente $35 \mathrm{~km}^{2 \prime \prime}$. Silva et al. (2016) revisita o Complexo Trincheira acrescentando novos dados de campo, descrições petrográficas e de assinaturas litogeoquímicas. 

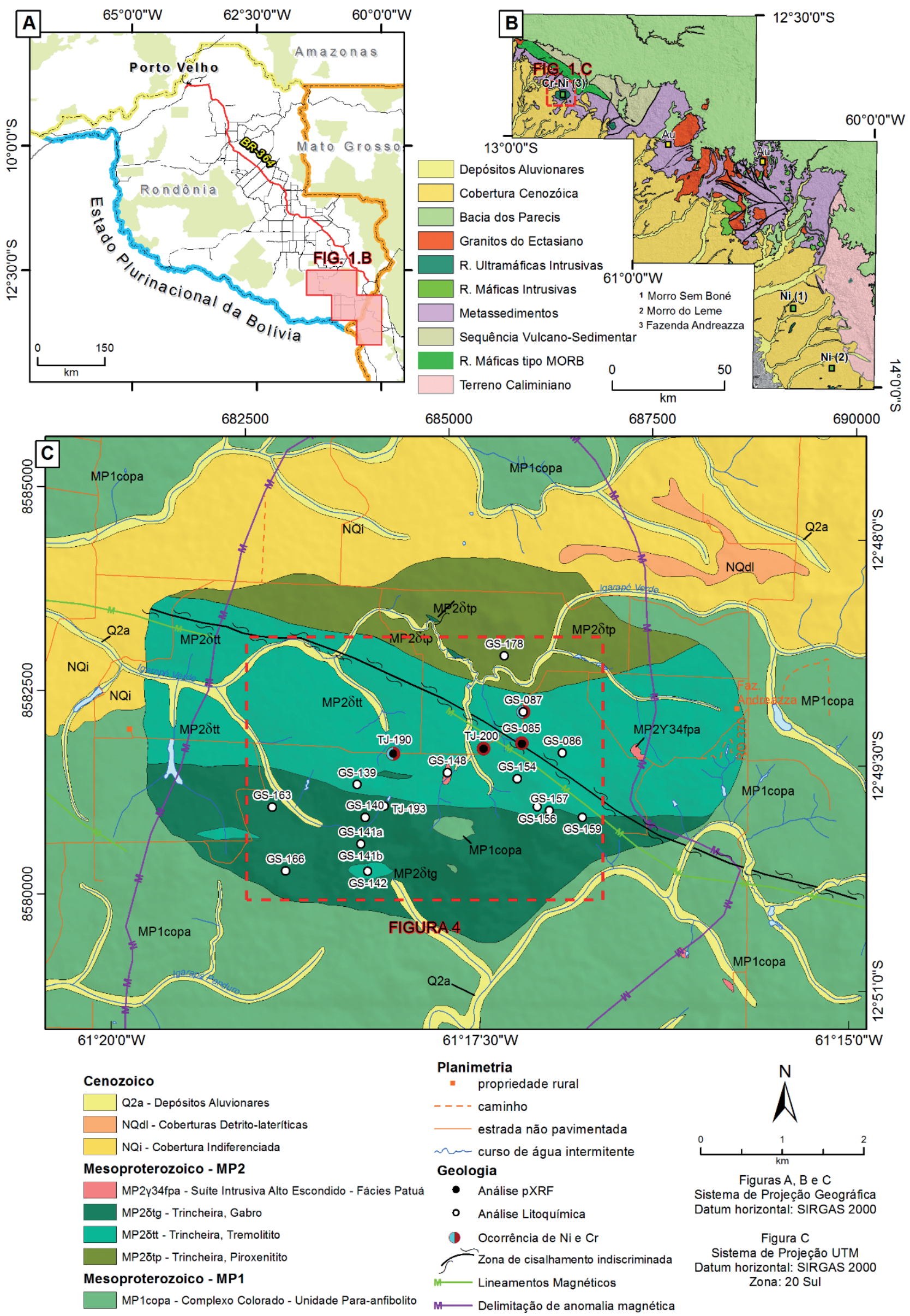

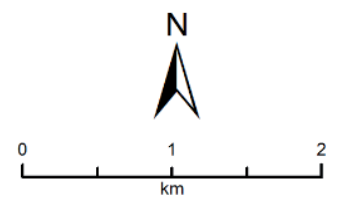

Figuras A, B e C

Sistema de Projeção Geográfica Datum horizontal: SIRGAS 2000

Figura $\mathrm{C}$

Sistema de Projeção UTM Datum horizontal: SIRGAS 2000 Zona: $20 \mathrm{Sul}$

Figura 1 - A) Localização da área do projeto entre os estados de Rondônia e Mato Grosso, próximo a fronteira com a Bolívia; B) Geologia simplificada do Projeto Sudeste de Rondônia (SILVA et al., 2016) e principais ocorrências minerais de níquel, cromo e ouro; C) Mapa geológico de detalhe da porção aflorante do Complexo Trincheira, incluindo a localização das ocorrências minerais de Cr-Ni (Co-V) e das estações com análises químicas e por pXRF (Fluorescência de Raios-X portátil, modelo Olympus DELTA Professional). 
O Complexo Trincheira é formado por corpos acamadados e tabulares, grosseiramente divididos de norte a sul por componente ultramáfica, que grada para rochas máficas. Estas rochas encontram-se pouco deformadas e localmente se transformam em tremolititos. As rochas encaixantes constituem uma sequência de rochas calcissilicáticas, paraanfibolitos e rochas metavulcânicas metamorfisadas em fácies anfibolito superior, que ocasionalmente ocorrem como xenólitos dentro do complexo.

Comparativamente, o corpo da Fazenda Andreazza se assemelha aos corpos ultramáficos de Morro Sem Boné e Morro do Leme, que são mineralizados em Ni (NUNES, 2000), situados no município de Comodoro (MT), a $100 \mathrm{~km}$ a sudeste das ocorrências aqui discutidas, na região próxima ao limite da Província Rio Negro-Juruena com a Faixa Alto Guaporé, ambos no mesmo contexto geológico (RIZZOTTO et al., 2013).

\section{DESCRIÇÃO DA OCORRÊNCIA}

Foram identificadas quatro amostras com concentrações relevantes de $\mathrm{Cr}$ e $\mathrm{Ni}$ que afloram como blocos subangulares a tabulares em meio a tremolititos e piroxenitos (Tabela 1). Três das ocorrências estão alinhadas paralelamente ao acamamento ígneo, de modo a sugerir fazer parte do mesmo horizonte.

Em afloramento, as rochas mineralizadas possuem uma capa de alteração de óxidos e hidróxidos de ferro, que conferem uma coloração avermelhada, podendo facilmente ser confundida com laterita. Quando frescas, apresentam coloração preta, com cristais sub-centimétricos de minerais de brilho metálico, alguns fortemente magnéticos, imersos em uma matriz de silicatos visíveis a olho nu.

O difratograma de raios- $X$ obtido para a amostra TJ-190 (Figura 2) indica a presença de silicatos piroxeníticos além de magnetita, magnesiocoulsonita (?) e cocromita (variedade de cromita enriquecida em Ni, $\mathrm{Co}$ e $\mathrm{Fe}$ ).

A natureza cumulática tanto das rochas encaixantes como das mineralizadas foi confirmada pela

Tabela 1 - Localização das ocorrências

\begin{tabular}{|c|c|c|}
\hline Afloramento & *UTM-E & *UTM-N \\
\hline GS-085 & 687411 & 8581659 \\
\hline GS-087 & 656913 & 8582233 \\
\hline TJ-190 & 684319 & 8581724 \\
\hline TJ-200 & 685428 & 8581181 \\
\hline
\end{tabular}

*Datum: SIRGAS 2000, zona 20 Sul. petrografia onde as amostras mineralizadas apresentam cristais cumuláticos de cromita e magnetita dispersos em uma matriz parcialmente serpentinizada (Figura 3).

\section{ANÁLISE QUÍMICA}

Dezesseis amostras de rocha foram coletadas ao longo do Complexo Trincheira (Tabela 2). As análises químicas foram feitas nos laboratórios da SGS Geosol. As concentrações de $\mathrm{MgO}, \mathrm{TiO}_{2}, \mathrm{CaO}$ e $\mathrm{FeO}_{\mathrm{t}}$, foram obtidos por leitura em fluorescência de raios- $X$ em amostras abertas com metaborato de lítio. Os teores de $\mathrm{S}$, $\mathrm{Cr}, \mathrm{Ni}, \mathrm{Co}, \mathrm{V}$ e Cu, foram obtidos utilizando ICP-MS após digestão multiácida. Já os valores de Pt foram obtidos por leitura de ICP-AES após fusão por fire assay.

De maneira complementar, foram aproveitadas três medidas realizadas in situ por fluorescência de raios-X portátil ( $p X R F$ ) durante os trabalhos de campo, que mostraram concentrações altas de cromo e níquel, e uma delas com concentração relevante de cobalto e vanádio (Tabela 3).

Estas análises foram compiladas de modo a simular uma possível estratigrafia da intrusão (Figura 4). Considerando que o corpo acamadado não está invertido, a porção ultramáfica (basal) está ao norte e as unidades máficas superiores ao sul. Deste modo, é possível observar os valores anômalos dos cromititos da amostra GS-087 em FeO, $\mathrm{Cr}$, Ni, Co e Cu comparado aos teores médios de suas rochas hospedeiras. Há uma correlação negativa entre as concentrações de enxofre e as de níquel, sugerindo que este último pode estar presente também em outra fase mineral que não a pentlandita, anteriormente descrita por Romanini (2001). 

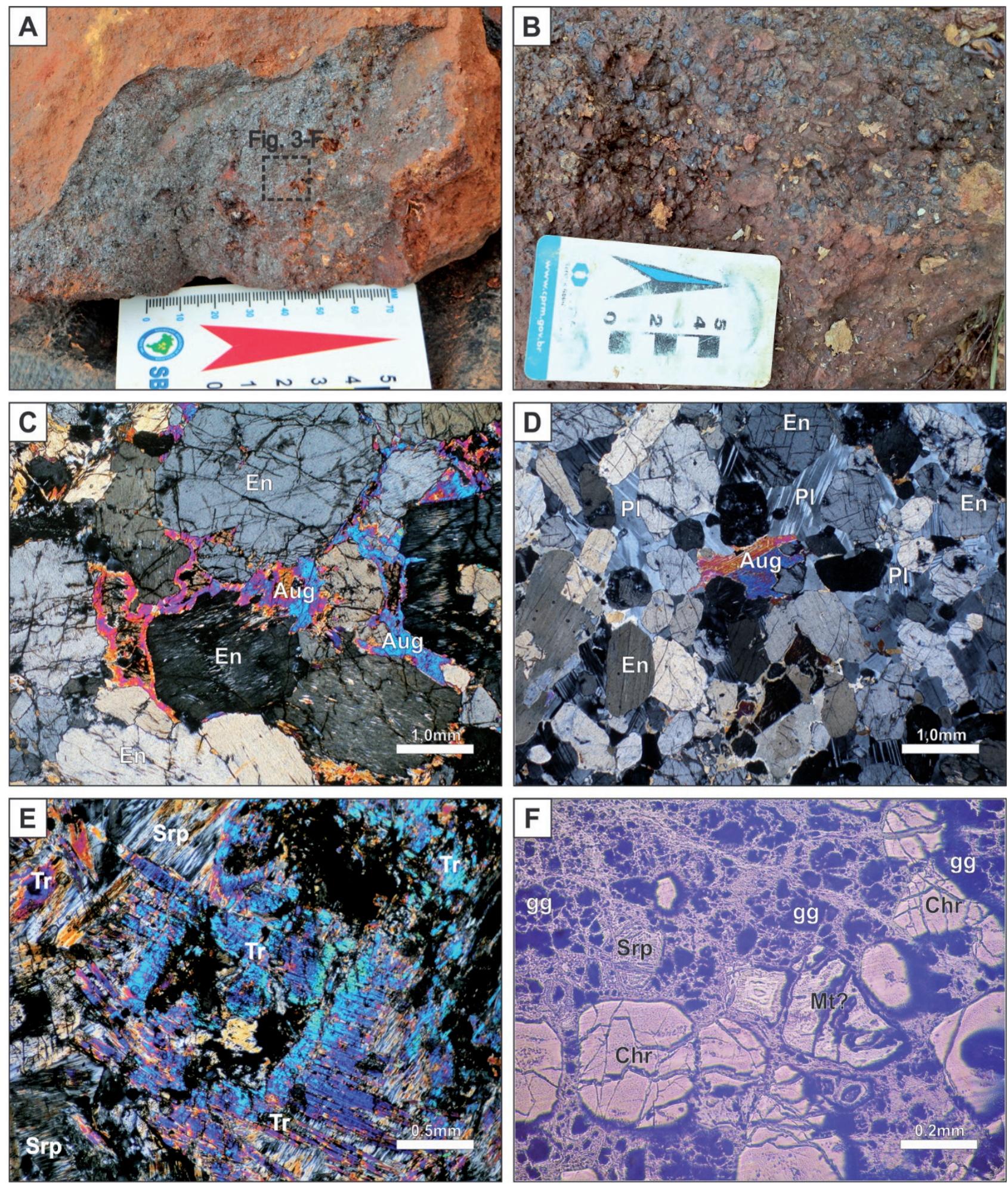

Figura 3 - A) Blocos de cromitito maciço que ocorre em meio a piroxenitos parcialmente tremolitizados, amostra TJ-190; B) cromitito cumulático com textura grossa parcialmente lateritizado, amos-tra GS-087; C) fotomicrografia com polarizador cruzado de websterito, composto por cúmulos de enstatita com intercúmulo de augita, amostra TJ-030; D) fotomicrografia com polarizador cruzado de gabronorito composto por cúmu-los de enstatita e augita,

dispersos em matriz de plagioclásio, amostra GS-092; E) fotomicrografia com polarizador cruzado de rocha metamórfica de protólito ultramáfico composta por tremolita, serpentina e opacos, sem trama planar bem desenvolvida, amostra GS-086; F) fotomicrografia de luz refletida de rocha onde pre-dominam cristais cumuláticos de cromita e magnetita com lamelas de exsolução de ilmenita, dispersos em matriz serpentinítica, seção polida da amostra TJ-190. Abreviaturas: En - Enstatita; Aug - Augita; PI - Plagioclásio; Srp - Serpentina; Tr - Tremolita; Chr Cromita; Mt - Magnetita e gg - Ganga. 
Tabela 2 - Resultados de análises químicas em amostras de rocha do Complexo Trincheira

\begin{tabular}{|c|c|c|c|c|c|c|c|c|c|c|c|c|c|}
\hline \multirow{2}{*}{ Amostra } & \multirow{2}{*}{ UTM_E } & \multirow{2}{*}{ UTM_N } & MgO & $\mathrm{TiO}_{2}$ & $\mathrm{CaO}$ & $\mathrm{FeO}_{\mathrm{t}}$ & $S$ & $\mathrm{Cr}$ & $\mathrm{Ni}$ & Co & v & $\mathrm{Cu}$ & Pt \\
\hline & & & $\%$ & $\%$ & $\%$ & $\%$ & $\mathrm{ppm}$ & $\mathrm{ppm}$ & ppm & $\mathrm{ppm}$ & $\mathrm{ppm}$ & ppm & ppb \\
\hline GS-086 & 686390 & 8581731 & 27,1 & 0,31 & 1,4 & 12,1 & $<0,01$ & 770 & 488 & 46,3 & 126 & 147,8 & $<5$ \\
\hline GS-087 & 685913 & 8582233 & 3,53 & 0,91 & 0,06 & 42,4 & 0,02 & 3624 & 1829 & 651,2 & 318 & 470,8 & $<5$ \\
\hline GS-139 & 683871 & 8581343 & 26,3 & 0,35 & 0,93 & 10,6 & $<0,01$ & 803 & 395 & 51,6 & 113 & 98,7 & $<5$ \\
\hline GS-140 & 683968 & 8580941 & 7,67 & 0,96 & 10,6 & 12,0 & 0,03 & 76 & 56,3 & 44,2 & 215 & 36,9 & $<5$ \\
\hline GS-141A & 683917 & 8580614 & 13,6 & 0,61 & 11 & 10,7 & 0,11 & 309 & 230 & 52,8 & 176 & 100,6 & 5 \\
\hline GS-141B & 683917 & 8580614 & 13,6 & 0,67 & 14 & 9,7 & 0,09 & 313 & 185 & 49,7 & 199 & 137,7 & 10 \\
\hline GS-142 & 684000 & 8580279 & 23,9 & 0,56 & 2,85 & 11,6 & 0,01 & 549 & 614 & 54,8 & 124 & 195,8 & $<5$ \\
\hline GS-148 & 684979 & 8581489 & 17,9 & 0,27 & 3,84 & 18,5 & 0,11 & 370 & 530 & 66 & 150 & 34,2 & $<5$ \\
\hline GS-154 & 685837 & 8581416 & 30,1 & 0,19 & 1,24 & 11,3 & 0,01 & 580 & 1286 & 75,3 & 68 & 26,8 & $<5$ \\
\hline GS-156 & 686081 & 8581070 & 28,0 & 0,28 & 0,68 & 10,7 & $<0,01$ & 763 & 500 & 66,1 & 103 & 14,6 & $<5$ \\
\hline GS-157 & 686232 & 8581023 & 28,3 & 0,19 & 2,32 & 9,9 & 0,03 & 525 & 641 & 73,4 & 77 & 71,7 & N.A. \\
\hline GS-159 & 686638 & 8580941 & 24,4 & 0,23 & 1,21 & 15,7 & 0,02 & 432 & 690 & 79,8 & 108 & 12 & 7 \\
\hline GS-163 & 682828 & 8581068 & 6,89 & 1,43 & 10,9 & 15,0 & 0,04 & 39 & 46,8 & 40,4 & 210 & 42,1 & $<5$ \\
\hline GS-166 & 682991 & 8580284 & 9,39 & 0,34 & 10,9 & 8,2 & 0,12 & 86 & 131 & 43,5 & 113 & 43,4 & $<5$ \\
\hline GS-178 & 685679 & 8582924 & 13,9 & 0,22 & 10,9 & 8,2 & 0,15 & 143 & 216 & 48,7 & 116 & 43,1 & $<5$ \\
\hline TJ-193 & 684203 & 8581081 & 6,08 & 1,65 & 11 & 13,4 & 0,14 & 14 & 9,9 & 37,8 & 258 & 36,3 & N.A. \\
\hline
\end{tabular}

Tabela 3 - Resultados químicos para ocorrências minerais analisadas por pXRF

\begin{tabular}{|c|c|c|c|c|c|c|c|c|c|}
\hline \multirow{2}{*}{ Amostra } & \multirow{2}{*}{ UTM_E } & \multirow{2}{*}{ UTM_N } & MgO & $\mathrm{TiO}_{2}$ & FeO & Co & Ni & Cr & $\mathbf{V}$ \\
\cline { 4 - 11 } & & & $\%$ & $\%$ & $\%$ & $\mathrm{ppm}$ & $\mathrm{ppm}$ & $\mathrm{ppm}$ & $\mathrm{ppm}$ \\
\hline GS-086 & 686390 & 8581731 & 27,1 & 0,31 & 12,1 & 770 & 488 & 46,3 & 126 \\
\hline GS-087 & 685913 & 8582233 & 3,53 & 0,91 & 42,4 & 3624 & 1829 & 651,2 & 318 \\
\hline GS-139 & 683871 & 8581343 & 26,3 & 0,35 & 10,6 & 803 & 395 & 51,6 & 113 \\
\hline
\end{tabular}

\section{COMENTÁRIOS FINAIS}

O Complexo Máfico-Ultramáfico Trincheira traz novos alvos prospectivos com associação química de $\mathrm{Cr}, \mathrm{Fe}, \mathrm{Ni}, \mathrm{Co}, \mathrm{V}$ e elementos do grupo da platina a partir do reconhecimento e caracterização de um provável horizonte de cromita cumulática dentro do corpo acamadado (podendo haver mais de um).

A quantidade de dados é insuficiente para fazer qualquer correlação que favoreça ou não a acumulação de níveis sulfetados. Até o dado momento, parece que a concentração de $\mathrm{Ni}$-Co pode estar nos óxidos, possivelmente em uma cromita cobaltífera, a cocromita, como principal mineral. Descrições anteriores relatam a presença de pentlandita como fase sulfetada no complexo (ROMANINI, 2001). Observou-se que as rochas enriquecidas em cálcio apresentaram as maiores concentrações de enxofre (gabros, gabronoritos e anortositos).
A Figura 5 sugere que a anomalia magnetométrica atribuída ao Complexo Trincheira ocorre em uma área muito superior àquela aflorante. Caso esta anomalia magnética represente de fato porções não aflorantes do complexo abaixo das rochas encaixantes calcissilicáticas contrastantes, o Complexo Máfico-Ultramáfico Trincheira terá seu potencial prospectivo significativamente ampliado.

Recomendam-se estudos de detalhe que visem reconhecer outros horizontes mineralizados, buscando verificar a extensão lateral e em profundidade destes corpos máfico-ultramáficos. Sugere-se também campanhas de gravimetria e magnetometria terrestre de detalhe, baseado no contraste de densidade e magnético observado em amostra de mão entre a rocha mineralizada e as demais. Trabalhos de polarização induzida (IP) podem ser realizados a fim de identificar possíveis níveis enriquecidos em platinoides e de sulfeto maciço. Estudos de microssonda trariam informações mais confiáveis sobre as fases minerais que abrigam os elementos siderófilos ( $\mathrm{Fe}$, $\mathrm{Ni}$ e $\mathrm{Co}$ ) e litófilos (Cr e Ti). 
A
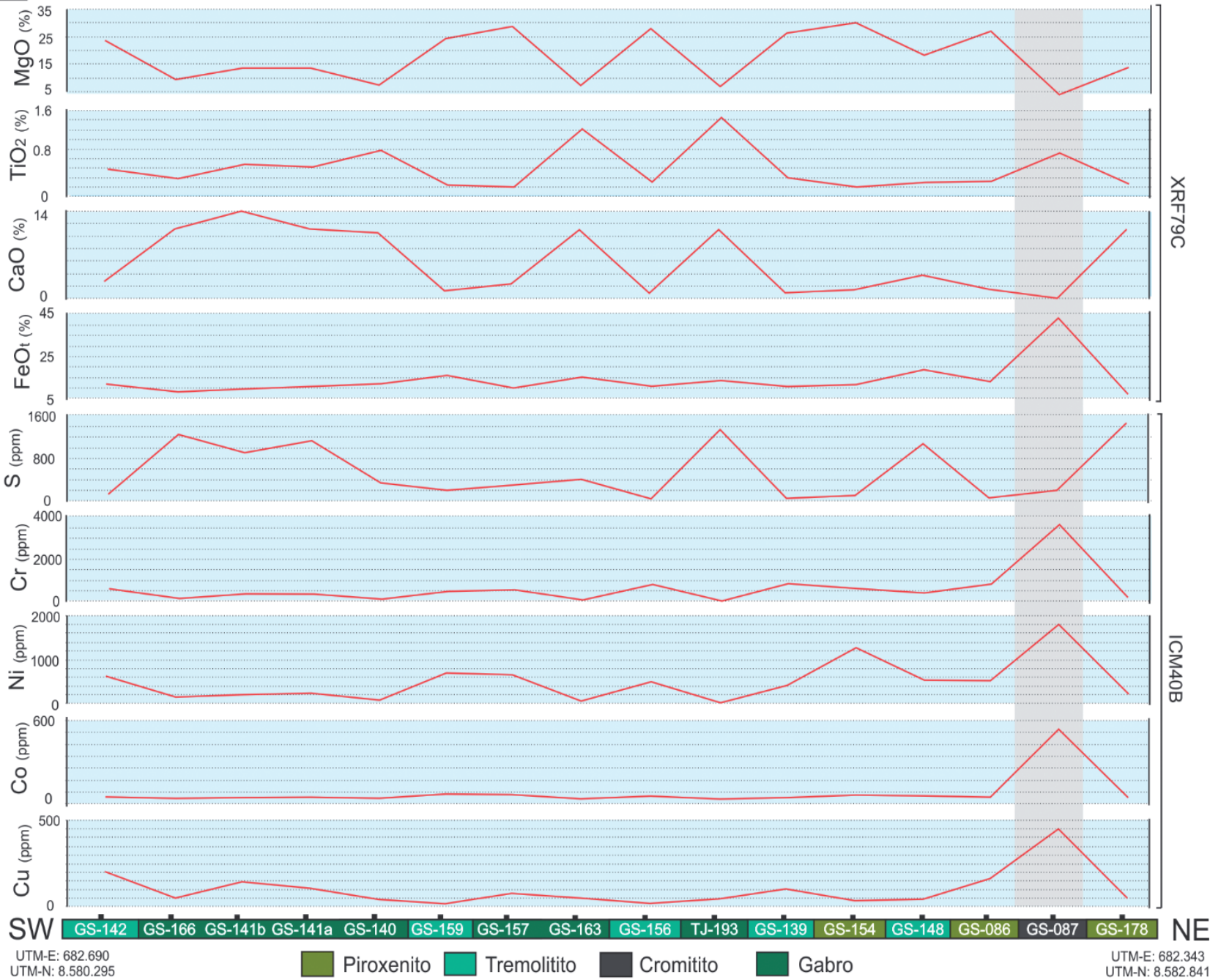

\section{B}
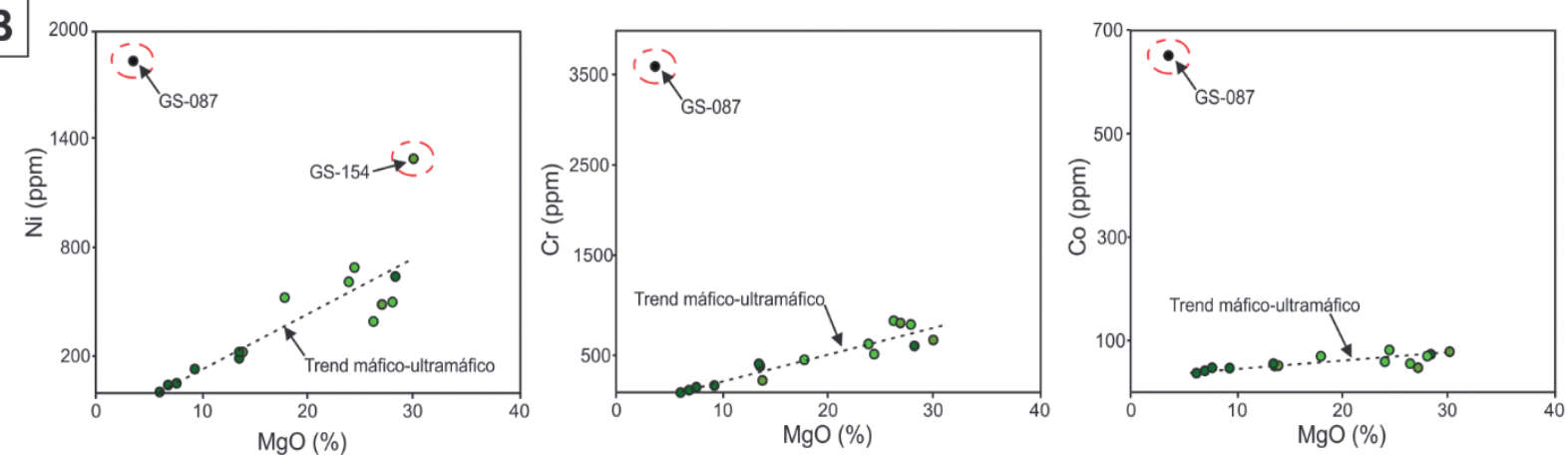

Figura 4 - A) Quimioestratigrafia do Complexo Trincheira a partir da projeção das análises químicas ao longo de um eixo intermediário aos afloramentos, de direção NE-SW, que cruza as litofácies (ver Figura 1). A cor associada às amostras na barra horizontal evidencia o litotipo conforme indicado na legenda. B) Diagramas binários de $\mathrm{Ni}, \mathrm{Cr}$ e Co (ppm) versus $\mathrm{MgO}$ (\%). Há uma correlação linear positiva forte com as amostras de gabros, piroxenitos e tremolititos nos três diagramas. As amostras GS-154 e GS-087 destacam-se com concentrações acima desta tendência em Ni e Ni, Cr e Co, respectivamente. A amostra GS-087 apresenta as maiores concentrações dos três elementos metálicos, mas possui baixa concentração de magnésio. Isso pode ser explicado por esta rocha ser composta de minerais cumulados de fase oxidada e menores quantidades de fases de silicatos ricos em magnésio (serpentina, piroxênios e tremolita). 


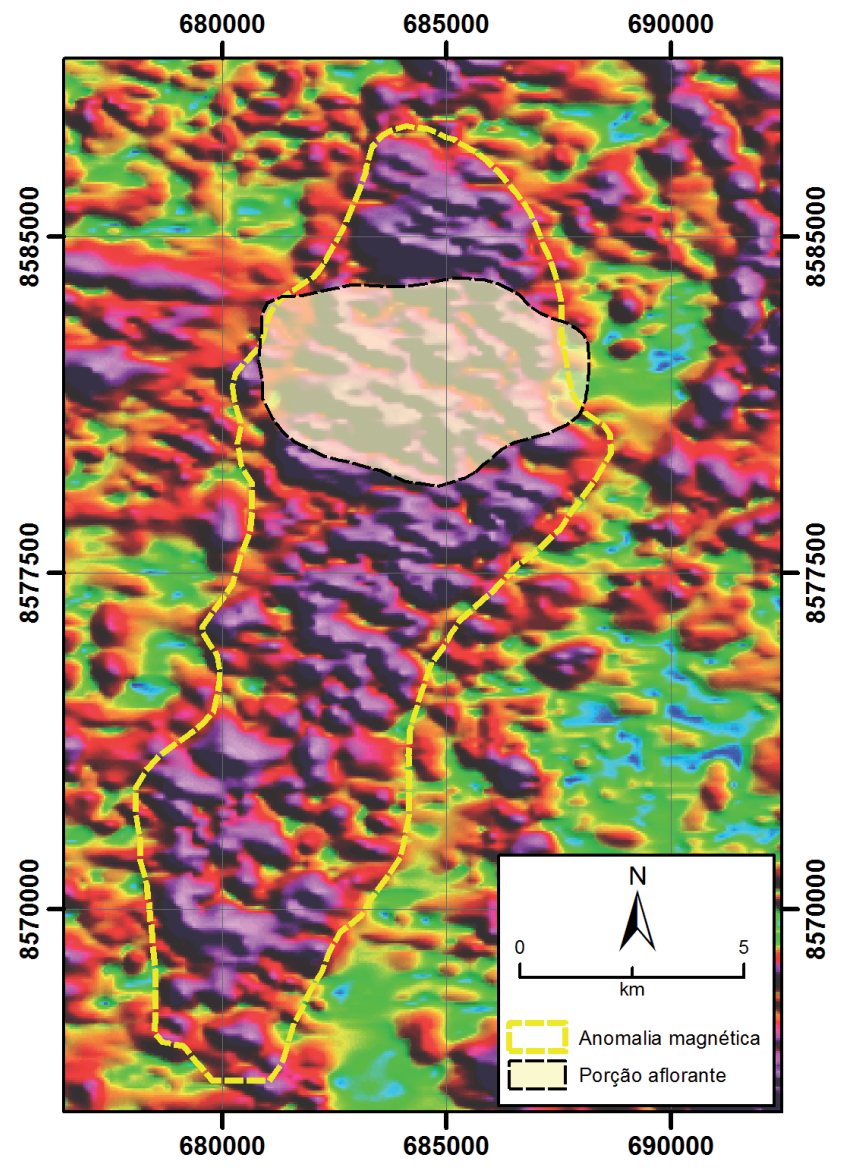

Figura 5 - Mapa Magnético de Gradiente Total com indicação de porção aflorante do Complexo Trincheira e sua extensão provável em sub-superfície, baseado na anomalia magnetométrica.

\section{REFERÊNCIAS}

NUNES, N. S. V. Geologia e Resultados Prospectivos das Áreas Morro do Leme e Morro Sem Boné, Mato Grosso. Goiania: CPRM, 2000. 56 p. (Informe de Recursos Minerais. Série Metais do Grupo da Platina e Associados, 19). Programa Nacional de Prospecção de Metais do Grupo da Platina - PNPP. Projeto Platina e Associados.

RIZZOTTO, G. J. et al. The Mesoproterozoic Guaporé suture in the SW Amazonian Craton: Geotectonic implications based on field geology, zircon geochronology and $\mathrm{Nd}-\mathrm{Sr}$ isotope geochemistry. Journal of South American Earth Sciences, v. 48, p. 271-295, 2013.

ROMANINI, S. J. Aspectos Geológicos, Geoquímicos e Metalogenéticos do Magmatismo Básico/Ultrabásico do Estado de Rondônia e Área Adjacente. Porto Alegre: CPRM, 2001. 164 p. (Informe de Recursos Minerais. Série Metais do Grupo da Platina e Associados, 28). Programa Nacional de Prospecção de Metais do Grupo da Platina - PNPP. Projeto Platina e Associados.

SILVA, G. F. et al. Mapa Geológico Preliminar Integrado Novas Fronteiras Sudeste de Rondônia. Escala 1:100.000, apresentado em escala 1:200.000. Porto Velho, RO: CPRM, 2016. Projeto Avaliação do Potencial Mineral do Sudeste de Rondônia.

\section{INFORME TÉCNICO N 11 \\ Brasília, maio de 2017. \\ ISSN: 2448-2242 \\ Publicação on-line seriada \\ CPRM - Serviço Geológico do Brasil. \\ Disponível em: www.cprm.gov.br}

CPRM - Serviço Geológico do Brasil

SBN - Quadra 02 - Bloco H, Ed. Central Brasília, $1^{\circ}$ andar Brasília - DF - Brasil

CEP: 70040-904

Telefone:(61) 2108-8400

www.cprm.gov.br

contatos: seus@cprm.gov.br evandro.klein@cprm.gov.br

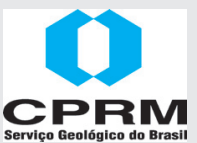

Diretor de Geologia e Recursos Minerais José Carlos Ferreira Garcia

\section{Corpo Editorial}

Evandro Luiz Klein (Editor)

Edilton José dos Santos

João Henrique Larizzatti

Luiz Gustavo Rodrigues Pinto

\section{Revisores}

Geysson A. Lages

Wilson Wildner

\section{Normalização Bibliográfica}

Nelma Fabrícia da P. Ribeiro Botelho

\section{Editoração Eletrônica}

Marcelo Henrique Borges Leão

Nelma Fabrícia da P. Ribeiro Botelho 